\title{
Chapter 10 \\ The Objective Approaches of Ethnic Origins in Belgium: Methodological Alternatives and Statistical Implications
}

\author{
Nicolas Perrin, Luc Dal, and Michel Poulain
}

\subsection{Introduction}

Massive twentieth century immigration in Belgium led to the emergence of a profoundly diverse society. However, until the 1980s, since a particularly restrictive nationality law was in force, it was believed that nationality-based distinctions adequately addressed the issue. But since 1984, the many reforms to the Code of Belgian citizenship have strongly challenged the consensus. In fact, Belgian nationality became one of the simplest national statuses to acquire in Europe, and nationality-based statistics reflect the action for nationality law and the consequences of the waves of immigration. Wedged between France and the Netherlands - two countries with radically different approaches to understanding diversity - Belgium has made the ethnic reference a taboo, especially in Frenchspeaking regions. However, the need to grasp the situation of foreign-born populations seems to be slowly gaining momentum from a scientific and political perspective, especially with regards to the nation's response to discrimination. Despite the marked divergences that still exist, the nation seems to be developing statistics on national origin based on objective criteria such as the place of birth and nationality of an individual and his/her ascendants, and, even though it is not

\footnotetext{
N. Perrin $(\triangle)$

Belgian Department of Immigration, Brussels, Belgium

e-mail: nicolas.perrin@ibz.fgov.be

L. Dal

Catholic University of Louvain (UCL), Louvain-la-Neuve, Belgium

e-mail: luc.dal@uclouvain.be

M. Poulain

Catholic University of Louvain (UCL), Louvain-la-Neuve, Belgium

Fond National de Recherche Scientifique (FNRS), Namur, Belgium

e-mail: michel.poulain@uclouvain.be
} 
used, this information is recorded by the extended administrative records system. This chapter presents the methodological choices that are emerging despite continuing opposition and their implications.

\subsection{Nationality-Based Statistics Assessment and Contemporary Issues}

\subsubsection{The Paradox of Foreigners' Demography: More Immigration, Fewer Foreigners}

At first glance, the change in the number of foreigners - people who do not hold Belgian nationality - seems paradoxical in Belgium. In fact, the past 25 years constitute the longest and most intense period of foreign immigration, which reached heights that were previously unseen even during active foreign labour recruitment phases. However, until very recently, the non-national population was apparently suffering from a stagnation of unprecedented proportions (Figs. 10.1 and 10.2). Officially, there were 903,736 foreigners in Belgium in 1981. On January 1, 2006, the number had dropped slightly to 900,473 , even though, in the meantime, net immigration had increased. It is only in recent years (2007-2008) that the rise in the number of foreigners has stabilized in the long term, surpassing historical figures.

Demographers will agree that if net foreigner immigration does not explain the stagnation in non-national population figures, neither will the population's birth and death figures. The number of deaths among foreigners continues to increase slightly as the immigrant population ages, but it remains lower than the number of births among foreigners, even in spite of a drastic reduction (Fig. 10.3).

The liberalization of the nationality law led to a stagnation in foreigner numbers. Until 1984, Belgium had a right to nationality inherited from the World War I period that made it difficult to acquire nationality, but successive reforms (notably 1984, 1991 and 1999) made Belgian nationality one of the simplest to obtain (Bauböck et al. 2006). Today in Belgium, the length of residence required for naturalization is 3 years, which is the minimum time required in Europe. In addition, nationality can be easily obtained in many cases through a simple declaration (after seven continuous years of residence, for example). Children born in Belgium of parents who were also born in Belgium easily acquire Belgian nationality at birth, as do the children whose parents have resided in the country for the past 10 years. ${ }^{1}$

\footnotetext{
${ }^{1}$ The liberalization of the Code of Belgian nationality is currently a subject of debate, especially in the Dutch-speaking region. Given the sensitivity of the issue, the legal changes that could have an impact in the short term are difficult to predict. However, preliminary accords seem to indicate that more rigorous nationality acquisition requirements, including changing the length of residency in view of naturalization from 3 to 5 years and the addition of a requirement pertaining to the knowledge of at least one of the nation's official languages, will come into effect.
} 


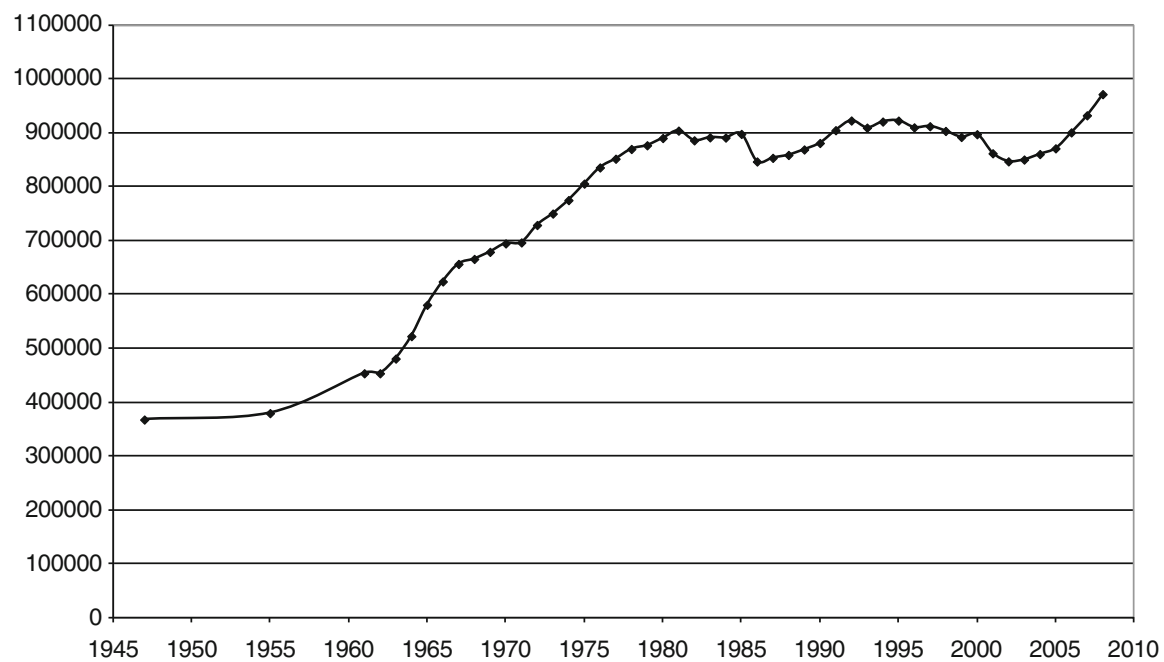

Fig. 10.1 Change in the number of foreigners in Belgium, 1948-2008 (Source: Population censuses and registers/Statistics Belgium)

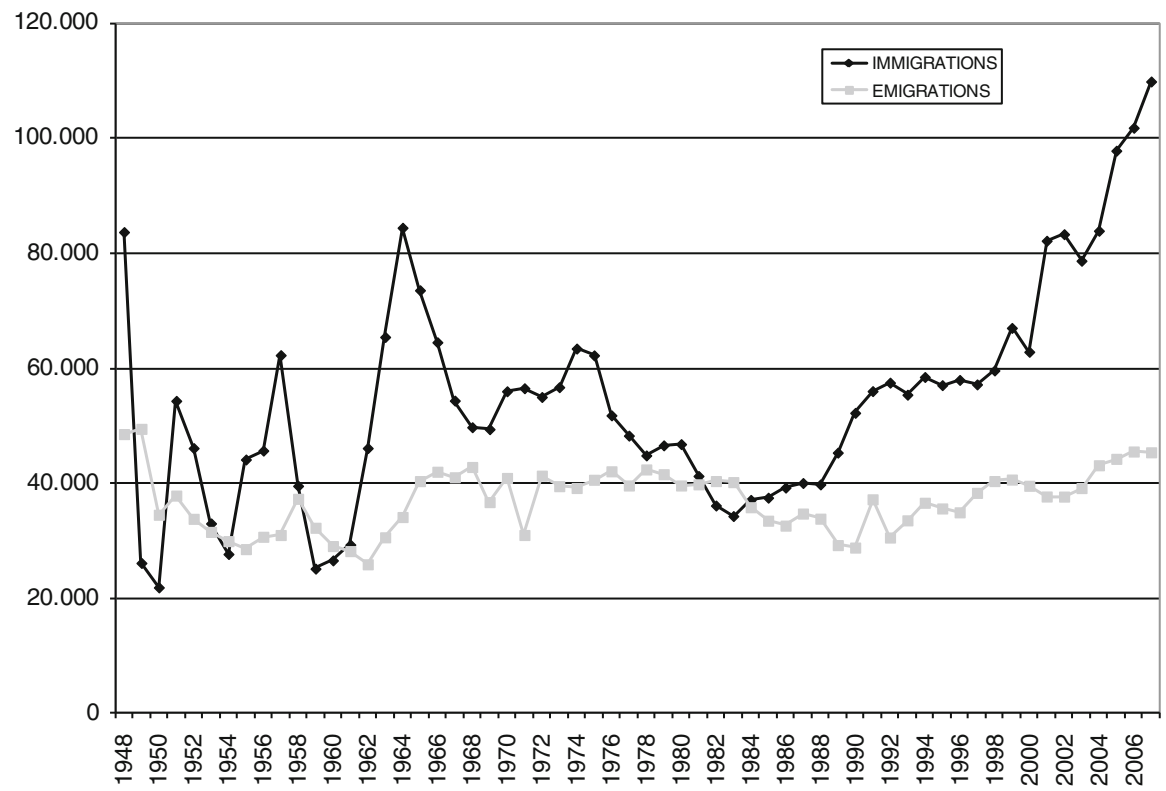

Fig. 10.2 Change in the number of foreign immigrations and emigrations, 1948-2007 (Source: Population registers/Statistics Belgium) 


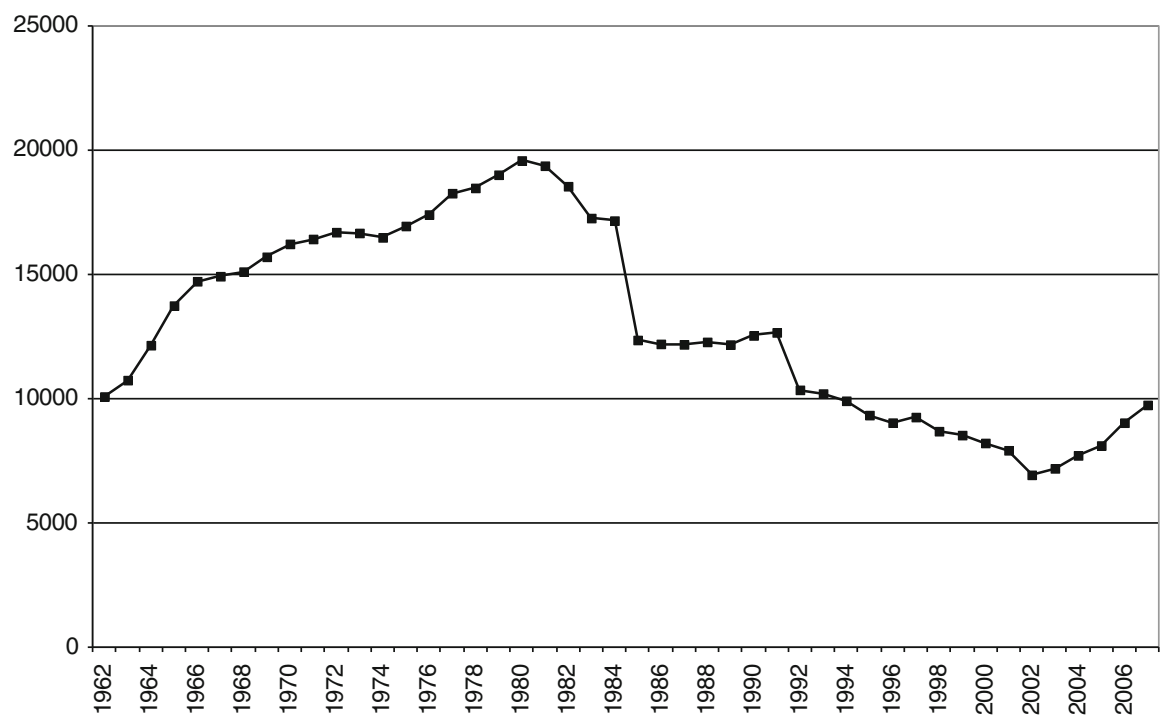

Fig. 10.3 Change in the number of births of foreigners, 1970-2007. Births of foreigners is the number of foreign children born in Belgium regardless of their parents' nationality (Source: Vital statistics/Statistics Belgium)

As reforms were implemented, the number of changes in nationality exploded a catch up effect that became the main factor in the evolution of non-national population figures (Fig. 10.4). The nationality law chiefly explains the decline in the number of foreigner births and the lesser natural dynamic of the non-national population. Though the fertility rate of non-national populations resembles that of Belgians, more than half of the decline in the number of foreigner births occurs in 2 years (1985 and 1992), when the number of foreigner births collapsed due to changes in at-birth nationality attribution regulations. Beginning in 1985, children born of a foreign father and Belgian mother were given Belgian nationality at birth while, in previous years, only children born of Belgian fathers obtained nationality. In 1992, children born in Belgium of non-national parents born in Belgium or residing in Belgium for at least 10 years could obtain Belgian nationality (Fig. 10.32).

The nationality law therefore impacts the demographic evolution of the nonnational population, which does not translate the demographic consequences of foreign immigration but rather the interactions between immigration and the nationality law. When the Code of nationality is stringent, the difference is negligible, but when the right to nationality is liberalized, the difference becomes more difficult to ignore, especially in transition periods.

\footnotetext{
${ }^{2}$ Births of foreigners is the number of foreign children born in Belgium regardless of their parents' nationality.
} 


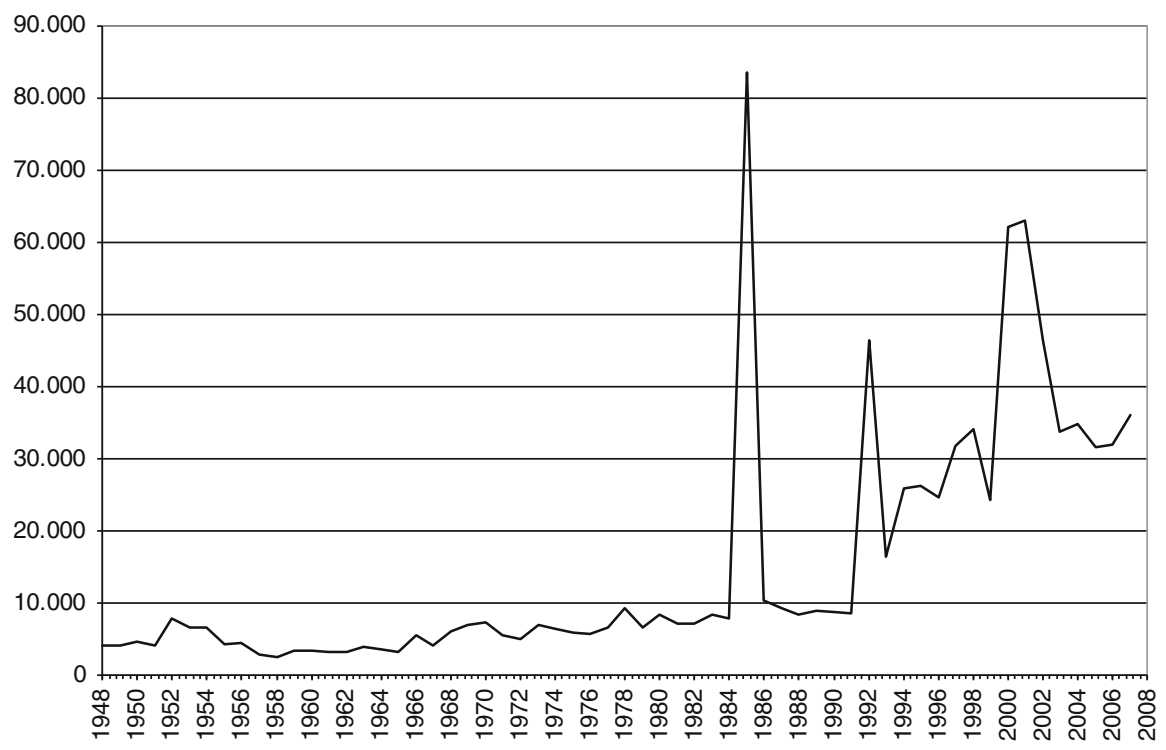

Fig. 10.4 Change in the number of foreigners who obtained Belgian nationality, 1948-2007 (Source: Statistical yearbooks and National Register (NR)/Statistics Belgium)

\subsubsection{Statistical Analysis and Reverse Conclusions}

Though non-national population development patterns may seem contradictory, accounting for all of the factors that impact their evolution (i.e. births and deaths, migrations and the particular dynamic of the nationality variable) explains these apparent incongruities. Disregarding the specificities of the nationality dynamic when studying nationality-based data could lead to reverse conclusions when analysing the non-national population.

The first challenge to assessing non-national population data lies in the extreme variability of the nationality law from one nation to another. Given the different legislation, comparing the nationality-based statistics of states sheds light on the differences in migratory histories and the intensity of these migrations but also (and perhaps even more so) on the differences in the nationality law. Small countries such as Luxembourg and Cyprus are among the European nations with the largest non-national populations, but so are nations with more restrictive nationality laws such as Latvia, Estonia, Germany and Austria. However, non-national populations are smaller in France and the United Kingdom, which both have more liberal nationality law.

In addition, since a nation's nationality law can change quickly, the evolution of an indicator may actually translate the evolution of the law rather than the phenomenon itself. Therefore, the evolution in the number of foreigners or foreigner births in Belgium is chiefly a sign of the changes brought to the Code of nationality in 1985, 1992 and 1999 (Figs. 10.1 and 10.3). 
The third difficulty in relying on nationality stems from the means of individuals to change nationality in their lifetimes. Because nationality is acquired differently according to variables such as age, length of residence, knowledge of the national language, nationality of a spouse, etc., simply analyzing population structures based on the nationality of individuals at a given time can be highly biased. The simple assessment of immigrant biographies highlights the fact that nationality acquisition varies significantly based on an immigrant's nationality of origin. With regards to EU-15 nationals with total settlement rights, the rate of nationality acquisition after 14 years is only $5 \%$. However, when examining the figures for the Turkish, Moroccan and Rwandan populations, the rate is $80 \%$. For the Congolese and Polish groups, the rate is $70 \%$ (Fig. 10.5). The demographic contribution of non-EU populations is most often underestimated when it is based on nationality alone. Generally, the non-national population represents a relatively biased subset as compared to the immigrant population. The probability of remaining in the country without becoming Belgian therefore significantly decreases over time, and recently-landed immigrants are strongly over-represented. The risk of bias when measuring themes such as entrance into the labour force is obvious since newly-landed immigrants are not representative of the entire immigrant population.

Just as the people who become Belgian have life stories and characteristics that are different from those of people who remain foreigners before acquiring their nationality, new Belgians may also have different destinies from those of the people

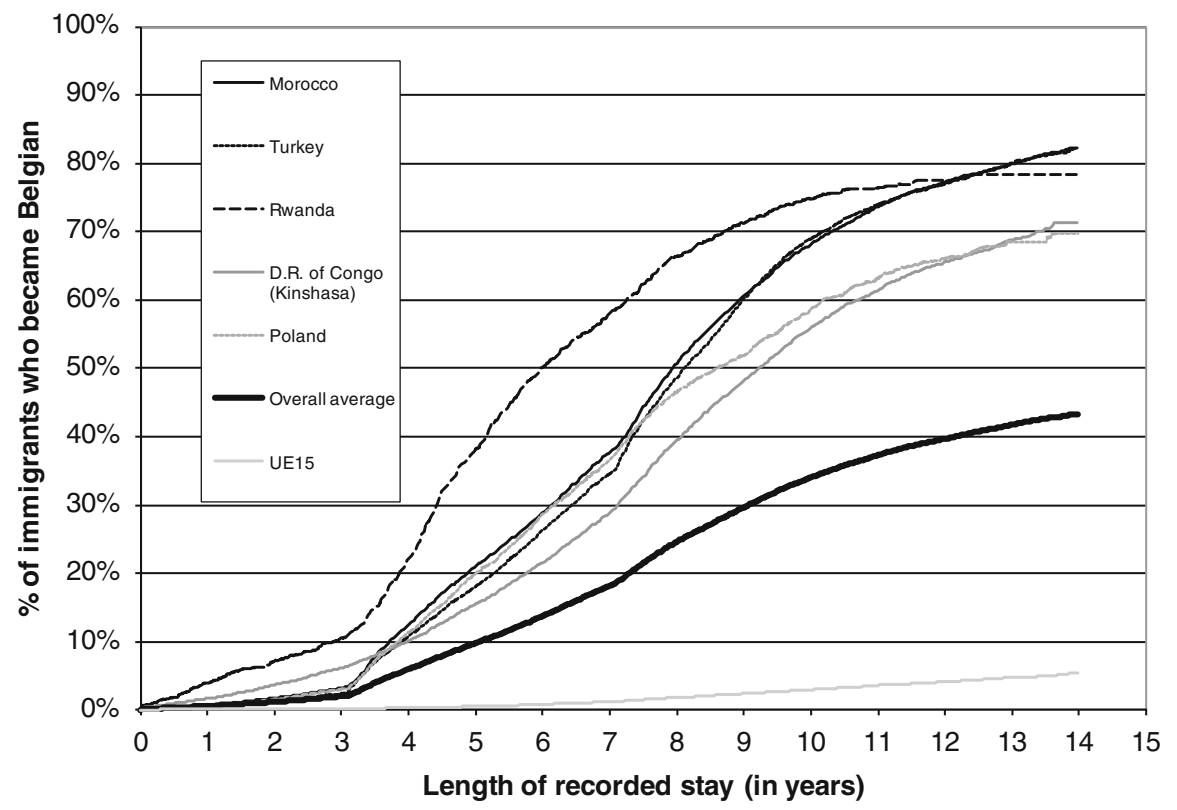

Fig. 10.5 Belgian nationality acquisition according to nationality of origin and length of stay (immigrants who arrived between 1991 and 2001) (Source: NR - Statistics Belgium/Authors' calculations) 
who remain foreigners after changing nationality. There is therefore a risk of not correctly capturing the situation. The circumstances of foreigners in the labour force is therefore very difficult to understand given the relatively transitory nature of the foreigner status and the greater number of job opportunities available to nationals (Vertommen et al. 2006).

Another obstacle to the use of nationality rests in the fact that Belgian nationality is not exclusive. Since 1999, new Belgians may hold more than one nationality, and the perception of this nationality may vary based on the perspective. When a Belgian person holds several nationalities, he/she is considered only as Belgian in Belgian statistics.

Finally, the most complex aspect of nationality to account for is the parent-child transmission of nationality, since the children of foreigners are not necessarily foreigners. They may be Belgian if one of their parents is Belgian, if one of their parents becomes Belgian before the child is born, if one of their parents was born in Belgium, if one of their parents has resided in Belgium for at least 10 years, etc. However, children will not benefit from these measures if their parents do not take the necessary steps. Since all of the legal elements were significantly modified recently, the probability of being born Belgian greatly depends on a child's year of birth. With regards to foreign children born in Belgium, an exceptional situation arises since age is completely ignored as a determining factor in nationality acquisition in favour of the circumstances when the successive changes to the Code of nationality were implemented. For children born in Belgium who obtain Belgian nationality, the main element that determines the probability of becoming Belgian is clearly circumstances since there is a net increase in the probability of becoming Belgian, irrespective of the child's age, around the time that the right to nationality reforms were implemented (primarily 1992 and 2000).

\subsubsection{A Necessary Reflection on the Analysis Categories}

Because nationality-based statistics do not make it possible to appreciate the true medium-term impacts of migrations and the characteristics of immigrant populations, it is necessary to assess the meanings of these statistics, their possible uses, their limitations and the possibility of developing better origin indicators.

In certain cases, nationality remains relevant, at the heart of the fundamental differences between citizens' and foreigners' rights (right vote, residence rights, right to hold certain professions or positions, etc.). A crucial part of the migration policies relies on increased control over foreigners who enter into the country and take up residence. For many reasons, it is useful for the state to be able to follow the changes and characteristics of the non-national population.

However, the use of non-national population statistics to better understand immigrant populations is no longer suitable because of the strong impact of the nationality law and the history of migration in Belgium. 
The integration and discrimination of the immigration population must be thoroughly assessed, but nationality does not make it possible to correctly understand the target-populations of these laws because the nationality prism is too distorting. Firstly, nationality does not determine whether or not a person will suffer from origin-based discrimination, since many of the people who are discriminated against because of their origin are, in fact, Belgian citizens. Also, integration policies are explicitly aimed at the broad immigration population and not the foreigner population because the foreigner status mainly impacts people who remain for illegal stays, legal immigrants during their first years in the country and nationals from developed nations (European Union, United States, Japan, Canada, Australia, New Zealand, etc.). Continuing to capture the origin of the population based on nationality and refusing to develop new origin indicators are therefore not neutral choices.

\subsection{Possible Alternative Definitions for Immigration Populations}

\subsubsection{Foreign Examples}

Nationality is a variable for which statistics are most widely collected in Europe and, until recently, was the central variable for many analyses examining the impacts of migrations. But there are many alternatives that provide a better idea of origin.

The best way of knowing a person's origin is to ask the person to declare it. Identifying individuals based on their ethnic or racial origin is a prevalent solution in Anglo-Saxon nations. Though, theoretically, self-identification (an individual declares his/her own origin) makes it possible to grasp the identity components, the practice may be rejected by certain groups concerned about misuse. Alternatively, people may falsely identify themselves as being part of more privileged groups. However, the hetero-identification of the ethnic or racial origin of individuals based on external opinion is also problematic since it supposes an outside judgement about the person that could be questionable or suspected of reinforcing discrimination. In sum, it is very difficult to determine a simple solution to the ethnic and racial identity issue.

Linguistic practices may also constitute a basis on which to categorize individuals according to their presumed ethnicity, as is the case in several European nations (essentially Eastern and Central European nations). However, multilingualism could pose a problem.

Eastern and Central Europe also developed cross-classifications for these indicators. Distinctions are made based on (1) nationality, (2) ethnic nationality or ethnicity, which is declared on a voluntary basis, and (3) mother tongue.

From a perspective that is more focussed on measuring the impacts of migrations rather than the ethnic origin of individuals, certain nations have developed origin 
categories based on objective data such as the place of the birth of individuals and their ascendants. Accounting only for foreign-born people makes sense in countries that consider themselves to be immigrant-receiving nations. However, the drive to rely on the situations of the second and third generations (people born of immigration who are not immigrants themselves) often leads back several generations in a person's genealogy. Therefore, in the Netherlands and Norway, status is based on the country of birth of the person's parents. In more detailed investigations, the country of birth of grandparents may be considered. This type of classification is problematic in countries where a large part of the population of nationals was born abroad (former colonies or temporarily expatriated populations). Based on their places of birth, these people will be considered as part of the immigrant population.

\subsubsection{Operationalization Limitations in Belgium}

Using data that is more precise than simple nationality information is necessary for experts seeking to understand discrimination and integration, but the idea of developing alterative indicators was not politically feasible until recently given the limited uses of the statistics in integration and anti-discrimination policy follow ups, the lack of knowledge of the limitations of the available statistics, opposition on part of the scientific community, decision-makers' choices regarding the use of ethnic statistics, certain statutory bans with regards to data collection, and other factors.

\subsubsection{Statutory Bans}

Public statistics have long hid behind the public statistics act to only publish nationality-based data: 'En aucun cas, les investigations et études statistiques de l'Institut national de Statistique ne peuvent concerner la vie privée, les opinions ou activités politiques, philosophiques ou religieuses, la race ou l'origine ethnique.' [Under no circumstances should the statistical studies and investigations of the National Statistical Institute comprise privacy, political, philosophical or religious opinions or activities, race or ethnic origin' (article $24 \S 5$ of the July 4, 1962 act, modified on August 1, 1985)]. The act is also clear on privacy protection: 'Le traitement de données à caractère personnel qui révèlent l'origine raciale ou ethnique, les opinions politiques, les convictions religieuses ou philosophiques, l'appartenance syndicale, ainsi que le traitement des données relatives à la vie sexuelle, est interdit.' [It is prohibited to process personal data on racial or ethnic origin, political opinions, religious or philosophical convictions and union membership as well as data on sexual life]' ${ }^{3}$

\footnotetext{
${ }^{3}$ The act also stipulates that this type of data may be processed in certain specific cases when it applies to scientific research in support of anti-discrimination policies.
} 
Though ethnic and racial origin research is prohibited, collecting data on places of birth and the nationality at birth of individuals and their ascendants is not. This interpretation has been confirmed since the Privacy Commission has authorized access to nationality at birth data several times, and it also seems as though data on parents' birthplaces could also be allowed.

\subsubsection{Ethical Ethnic Statistics?}

Those who seek the development of new origin-based statistics are of the opinion that current information does not provide an adequate portrait of the immigrant populations. Those who oppose this development believe that ethnic statistics could bolster discrimination and the ethnicization of society.

In Belgium, a nation divided on the subject between the Dutch-speaking north and the French-speaking south, the issue remains unresolved. The Dutch region quickly showed interest in the development of statistical follow ups on the discrimination suffered by immigrant populations, as is the practice in the Netherlands. However, like the French, Francophones are strongly opposed to ethnic statistics, and statistical distinctions based on origin remain taboo. Ethnic references are common in northern regions, where immigrant populations are most commonly referred to as non-natives (people from elsewhere or allochtone ${ }^{4}$ ) - a term clearly based on ethnicity and used to describe people of foreign origin, whether they are Belgian nationals or foreigners. In the southern region, the main reference is to nationality, and ethnic references are rare, even inappropriate (Jacobs and Rea 2005). Even the term ethnic statistics is viewed as out of place by those who oppose new originbased statistics. Francophone partisans of the development of this type of data avoid the term in favour of more neutral concepts such as statistics on origin, immigrant population or populations of foreign origin. But by the end of the 1990s, the impacts of this non-choice soon emerged.

In Flanders, despite a lack of data on the subject, integration policies were explicitly focussed on non-native populations, forsaking any reference to nationality (Carlier and Rea 2001), and quickly followed by the development of an originbased record through self-identification and patronymic analysis by specific administrations.

At the same time and on both sides of the linguistic divide, while public instances refused to generate ethnic statistics, academics were publishing studies to demonstrate the need for a new approach, releasing data on nationality at birth and drawing attention to the extent of the discrimination. While the debate on ethnic statistics stagnated, new origin-based statistics began to appear.

At the same time, in the political sphere, European anti-discrimination initiatives (Council Directive 2000/43/EC of 29 June 2000 implementing the principle of equal treatment between persons irrespective of racial or ethnic origin and Council

${ }^{4}$ From the Greek allos [other] and khthôn [land], as opposed to autochtone [native] (Dictionnaire Robert). 
Directive 2000/78/EC of 27 November 2000 establishing a general framework for equal treatment in employment and occupation) called for the development of more active policies and underscored the need to measure the phenomenon.

The Centre for Equal Opportunities and Opposition to Racism (CEOOR) therefore launched an initiative to examine the necessity and legitimacy of establishing socio-economic labour market monitoring to identify people based on their national origin. The basic conclusion of the preparatory work rested on a single question and answer: Because discrimination is based on ethnicity, why not implement an information tool to measure and remedy it? With a guarantee of privacy protection and controlled data collection and use conditions, it was impossible to oppose the development of such indicators in a society, which, despite a certain amount of denial, was marked by the ethnicization of social relationships leading to discrimination against the population of foreign origin. Given the methodological, legal and especially ethical and ideological constraints, it was decided to identify origin based on objective, anonymous and aggregated data from existing administrative databases. To reach the widest possible consensus, the patronymic, mandatory disclosure and voluntary self-identification approaches were rejected in favour of more neutral and objective data such as place of birth and the nationality at birth of individuals and their ascendants (Vanderkam 2006). Though ethnic statistics remained a sensitive issue, more neutral and objective origin-based data seemed to have gained political and ethical acceptance. With government support (interdepartmental meeting, May 2,2006 ), the conclusions of the preliminary study led to the implementation of a new working group to develop a concrete monitoring project. Not only did originbased statistics become more accepted, they were legitimized and sparked a methodological debate on how to best understand immigrant populations.

In September 2007, using the same arguments on the need to possess tools to better understand immigrant populations and the discrimination they suffered, the Statistical Office announced (DG-SIE 2007) that in light of the propositions formulated by the High Council for Statistics, it would publish data distinguishing native from foreign-born Belgians by identifying people born as foreigners and Belgian nationals at birth.

\subsubsection{Data Availability and Accessibility}

Given the legal limitations and intense ideological debate, ethnic and racial data, per se, does not exist. However, despite the strong opposition to the use of objective data, it should be noted that all such information, if it is not used for statistical purposes, is now available (or at least recorded) by administrative instances. Like most European nations, Belgium has population registers in which all legal residents, Belgians and foreigners are listed (Perrin and Poulain 2006). These registers contain data on the origins of individuals including their place of birth and nationality including its possible changes (Eggerickx et al. 2007). The files are organized in a way that makes it possible to identify members of a same household and their 
parentage, enabling experts to determine the place of birth and nationality at birth of parents. Today, the population registers are centralized in the National Register (NR), which is directly linked to certain administrative databases that include information on discrimination, especially in the workforce (CEOOR 2007). The most extensive of these databases is the Crossroads Bank for Social Security, which defines itself as the motor and coordinator of e-government in the social sector, and therefore receives information from all sector stakeholders and makes it possible to follow the activity of individuals.

Until now, the main challenge to the further use of the NR lies in the limitations of the use of the variable to establish parentage between individuals for statistical purposes. Parentage remains a particular variable to which, despite the centralization, kingdom communes must consent to providing access. In addition, communes are not obligated to collect information and enter it into the central database, though $95 \%$ of the population is accounted for.

This obstacle could be overcome by using the familial ties of household reference persons and all of the members of the household. Based on household makeup histories, it is possible to reconstitute the parentage of most Belgians. However, people who have never lived with their parents or who decohabitated from their parents before the NR was implemented (created in 1985 but communes recorded information from as far back as 1971) would not be identified. It may also be impossible to establish parentage in complex households in which several family nuclei cohabitate. However, in the future, the status of the parentage variable could be changed in order to directly identify family members based on parentage, even though this supposes strong political involvement.

\subsection{Alternative Statistics and the Impacts of the Definitions}

\subsubsection{Development and Criticism of Statistics on Nationality at Birth}

Though the dominant ideological position opposed any origin-based statistics beyond nationality, the first statistical data on immigrant populations based on variables other than nationality appeared in the 1990s and stemmed from the question on nationality at birth on the 1991 census and NR information.

The need to examine the distortions caused by the changes to the nationality law were originally born of demographic issues in light of the wild evolution in the number of births after the changes to the Code of Belgian citizenship (Van der Haegen 1990) and, more generally, of the biases impacting all nationality-based population indicators. Interactions between the nationality law and non-national population demography were quickly detailed by demographers. A draft solution 
was proposed (Debuisson and Poulain 1992) and led to a series of publications elucidating the evolution of the immigrant populations (Eggerickx et al. 1999; Poulain and Perrin 2002; Perrin 2008). NR historical records on nationality make it possible to identify nationals and foreigners and distinguish nationals who were Belgian nationals at birth from nationals who were not. Information on place of birth makes a distinction between true immigrants (born abroad) from people born in Belgium (third and second immigrant generations). The first year of registration in the NR makes it possible to determine a person's year of arrival and assess who arrived more or less recently.

At the same time, economists began to look at the job market for immigrant populations using coupled NR data to distinguish those who received Belgian nationality from those who were born with it and data from the Crossroads Bank for Social Security on job market activity (Vertommen et al. 2006).

From a demographic perspective, the first finding was the significant size difference between the non-national and population of foreign origin when looking at nationality at birth. On January 1, 2006, of the 1,625,362 people born abroad, 900,473 were foreigners and 724,889 were people who had obtained Belgian nationality (Fig. 10.6).

While the number of people with foreign nationality has remained stable, the number of people born as foreigners who did not receive Belgian nationality at birth increased significantly. In 1991, there were $1,189,836$ people born as foreigners. In 2006 , this figure grew to $1,625,362$ given the net increase in the number of people who acquired Belgian nationality.

In addition, the characteristics of people born as foreigners are very different from those of actual foreigners. Among foreigners, EU nationals account for $68 \%$ of foreigners and only $55 \%$ of people born as foreigners. Since third country nationals have a higher rate of nationality changes, the bias created when using nationality as a proxy of origin is greater among these groups. In fact, the same demonstration applies to most characteristics.

With regards to activity, the unemployment rate is overestimated because the employment rate of foreigners does not account for new Belgians but only foreigners who hold lower positions in the job market. However, though job market insertion is better for new Belgians, discrimination is manifest in terms of unemployment and level of position (Vertommen et al. 2006).

The final conclusion of the study is the need for further research. Nationality at birth enables researchers to appreciate a certain number of immigrant population characteristics but does not make it possible to perfectly understand all of the categories. For example, by including information on the ages of people born as foreigners, it becomes impossible to understand the young immigrant populations. There are fewer minors among those born as foreigners than in the Belgian-born population even though young people are an essential component of the immigration populations. In fact, in keeping with the nationality law, the children of immigrant populations are, most often, Belgian nationals at birth. 


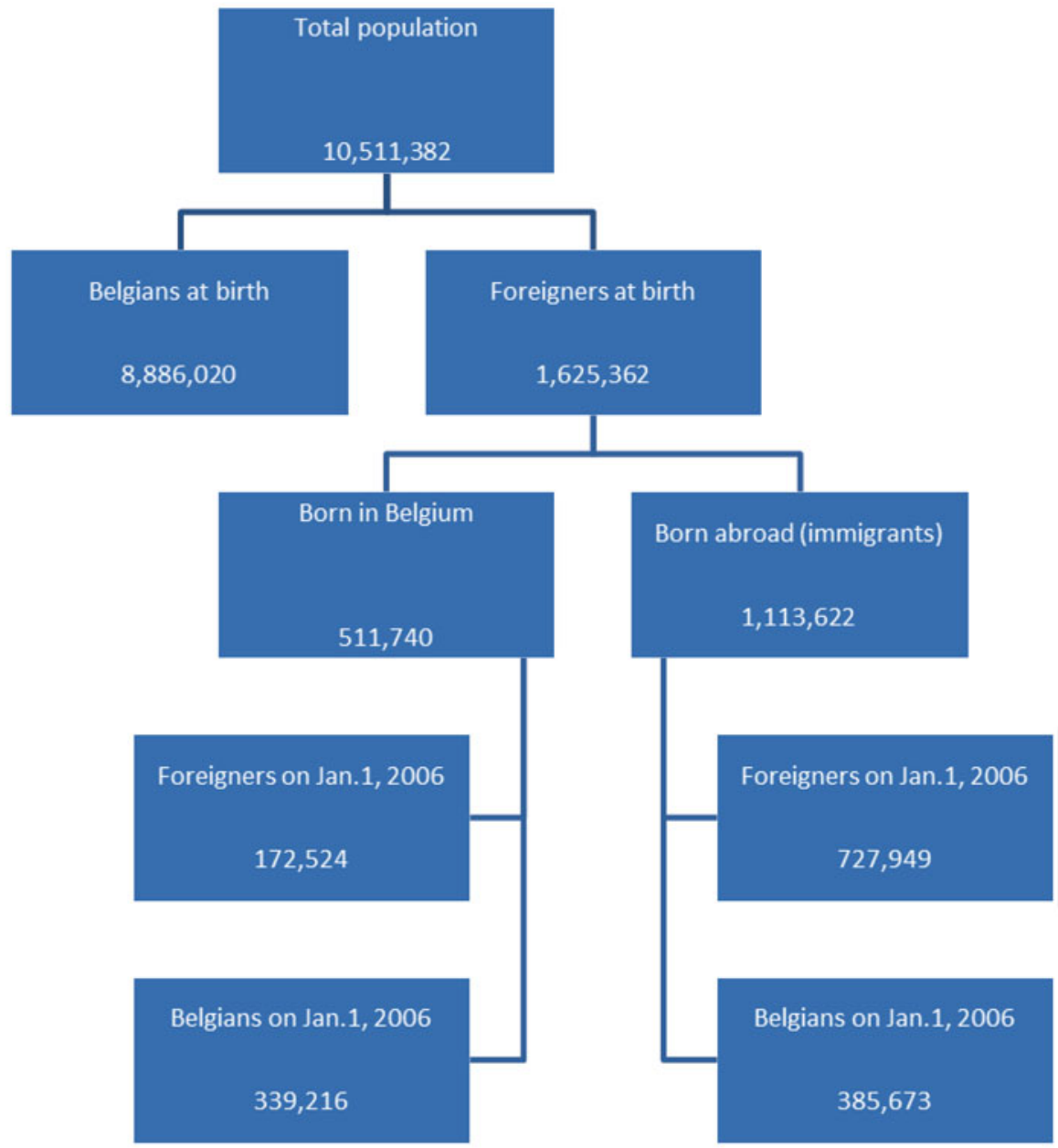

Fig. 10.6 Belgian population on January 1, 2006, based on nationality at birth, country of birth and current nationality (Source: NR-Statistics Belgium/Authors' calculations)

\subsubsection{Emergence of the First Estimations Based on Parent Characteristics}

The characteristics of children and parents must be linked in order to account for the Belgian-born children of immigration populations. In light of its sensitive nature, the parentage variable was first reconstructed based on household composition history. Despite the method's aforementioned flaws, ${ }^{5}$ the first estimates based on birth nationality of parents were released in 2007 (Poulain and Perrin 2008).

${ }^{5}$ See Debuisson and Perrin (2004). 
Based on these studies, as of January 1, 2006, it was estimated that 2,101,914 people had been born as foreigners or had at least one foreigner parent $-20 \%$ of the total population (vs. $15.5 \%$ when based on birth nationality). This group is therefore significantly larger than the non-national population and the population of people born as foreigners. It also appears that the total number of people with at least one foreign parent is increasing rapidly, even slightly faster than the number of people born as foreigners (Fig. 10.7).

By investigating a person's genealogy, certain cases of mixes that could not be identified when assessing only individual characteristics, including people who have a foreigner-born parent and a Belgian-born parent, began to appear. Among the Belgians born with at least one foreigner-born parent, there are only $23 \%$ with two foreigner-born parents. In $77 \%$ of cases, one parent is therefore Belgian-born.

These cases may be considered false since the grandparents of the Belgian-born parents may be foreigner-born. However, there is no source that traces grandparents $^{7}$ to provide a clear solution. In addition, relating back to grandparents supposes a hypothesis that is difficult to formulate on the influence that a grandparent's origin may have on a grandchild. Furthermore, going back three generations brings researchers to a period in which there was less immigration, and it is therefore important not to overestimate the significance of the third generation of immigration that does not appear in the statistics.

The methodological difficulties in the treatment of the data pertaining to the mixed origins of parents lead experts to question the idea of collecting information on grandparents despite the interest in the third generation. Because the rate of mixed origins in parents seems high, then the rate of mixed origins of grandparents could be remarkably high. What is the best way to consider a Belgian-born individual with three Belgian-born and one foreigner-born grandparent?

However, observing the mixed origins of parents is of sociological importance and should therefore incite experts to take great precaution when treating data on Belgian-born people of foreigner-born parents. There is no simple way to categorize people who have one parent of Belgian origin and another from abroad, and people may be discriminated against based on their origins. It could therefore be constructive to assess the extent of the discrimination. On the other hand, if a person is considered to be of Belgian origin in his or her everyday life, categorizing this person as being from an immigration population may be abusive.

From a methodological perspective, the proposals of the CEOOR workgroup are fairly similar to the first estimates, and the idea is to combine the information on nationality, birth nationality and countries of birth of individuals and their parents. However, the government should be involved in the publication of such data, which would lead to the generalized use of the information and better developed indicators.

\footnotetext{
${ }^{6}$ In light of the biases raised, the exactitude of the figure is deceptive.

${ }^{7}$ Because the National Register is a recent source, the genealogical information is not extensive enough to retrace more than two generations.
} 


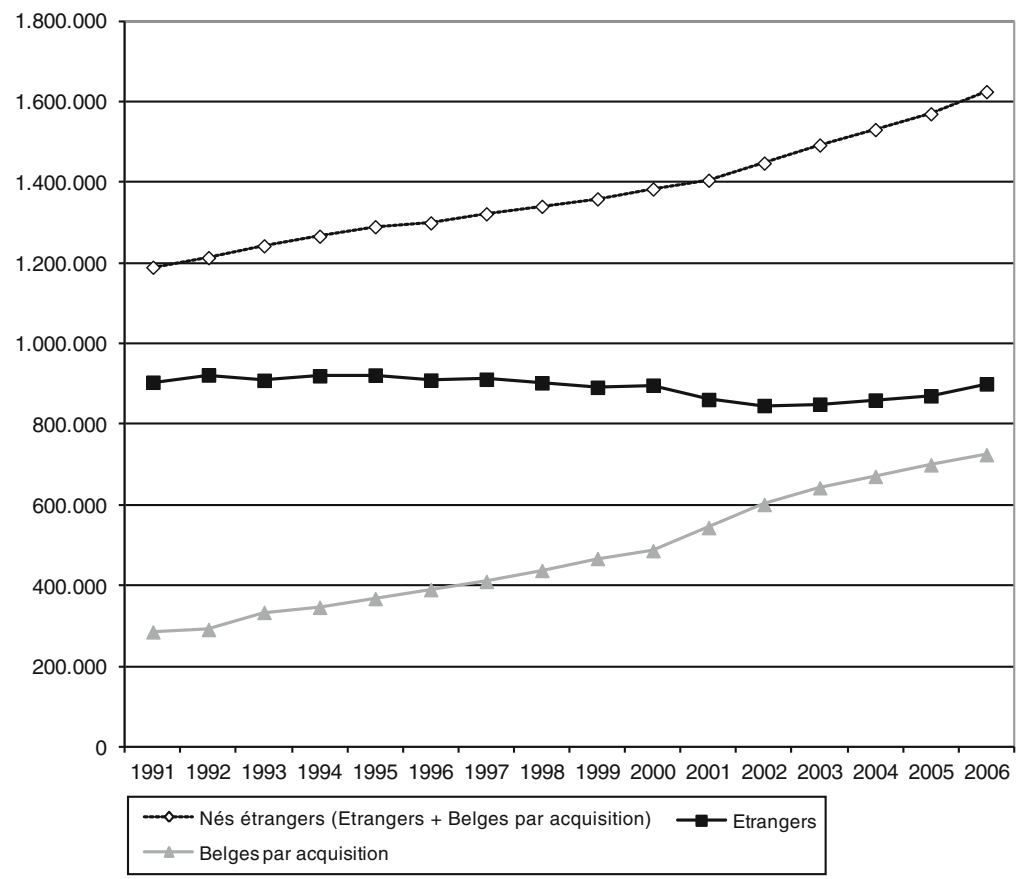

Fig. 10.7 Change in the foreigner and foreign-born populations according to the definition, 19912006 (Source: NR - Statistics Belgium/Authors' calculations)

\subsection{Conclusion}

Given the extensive liberalization of the Code of nationality in Belgium, it is no longer possible to use nationality-based data to understand immigrant populations. Nationality-based statistics are useful to understand the populations affected by the limitations of foreigner rights but do not provide any information on the impacts of migration because of the interactions between migration and nationality dynamics (the dynamics of acquiring a nationality and attributing nationality at birth in the case of newborns).

For many years, the development of new origin-based statistics was curbed by the dominant and open opposition to ethnic statistics, especially among the Frenchspeaking population. But opposition to the development of tools to better understand immigrant populations subsided as Belgian society progressively recognized its ethnicization and especially as it became impossible to deny origin-based discrimination and the need to strengthen the policies to counter it. Generating truly ethnic statistics remains controversial, but the development of origin-based indicators from objective data such as nationality at birth or the country of birth of parents seems to be widely accepted. 
Though these statistics are not officially available, the data on which they will be based is already recorded and available via the administrative registration system. For many years, academics have been creating indicators that make it possible to go beyond the biased vision that official statistics provide.

Generalizing these statistics should make it possible to better understand discrimination. If the criteria chosen to define origin are considered to be objective, it is best to insist on the close relationship between the choice of criteria, their scheme and their results/analysis. In light of previous studies, the resulting biases are far from negligible. Choosing to use only nationality to measure diversity creates a bias in the analysis. Examining nationality at birth overcomes certain challenges but yields a flawed picture of population origins. Referring to parental characteristics, which should be possible, will help overcome these obstacles and underscore the importance of the mixed origins of immigrant populations. Some would like even more information to understand the third immigrant generation in spite of the lack of data and the characterisation difficulties that arise when going so far back in time.

Progress has been made, but it is necessary to acknowledge the intrinsic limitations of objective categorisation and the preference for non-categorization. Though these choices may seem consensual, they are not neutral and largely determine the analysis. Therefore, even if objective data makes it possible to better understand immigrant populations, the possibility of collecting data on the ethnicity declared by individuals would help experts better understand the discrimination process and better appreciate the limitations and biases that impact the official statistics that objective elements yield.

Open Access This chapter is distributed under the terms of the Creative Commons Attribution Noncommercial License, which permits any noncommercial use, distribution, and reproduction in any medium, provided the original author(s) and source are credited.

\section{References}

Bauböck, R., Ersbøll, E., Groenendijk, K., \& Waldrauch, H. (Eds.). (2006). Acquisition and loss of nationality: Policies and trends in 15 European states. Vienna: Institute for European Integration Research, Austrian Academy of Sciences.

Carlier, J. -Y., \& Rea, A. (2001). Les étrangers en Belgique. Belgium: Dossiers du CRISP n 54.

Centre pour l'égalité des chances et la lutte contre le racisme (CEOOR). (2007). Monitoring socioéconomique basé sur l'origine nationale pour mieux lutter contre les discriminations sur le marché du travail.

Debuisson, M., \& Poulain, M. (1992). Des étrangers, des immigrés... Combien sont-ils en Belgique? Louvain-la-Neuve: Academia, Collection Migrations et Espaces, n2.

Debuisson, M., \& Perrin N. (2004). Essai de typologie concernant les populations étrangères et proposition de tableaux. Conseil supérieur de statistique, Révision des statistiques démographiques (19 p).

Direction générale Statistique et Information économique (DG-SIE). (2007). Plan d'action de la $D G$-SIE en matière de révision des statistiques démographiques. Brussels: DG-SIE.

Eggerickx, T., Kesteloot, C., Poulain, M., et al. (1999). La population allochtone en Belgique. Brussels: Institut National de Statistique. Monograph 3 of the March 1, 1991 census. 
Eggerickx, T., Perrin, N., \& Thomsin, L. (2007). Les sources statistiques et démographiques sur l'immigration et les populations étrangères en Belgique du $19 \mathrm{e}$ siècle à nos jours. In M. Martiniello, F. Dassetto, \& A. Rea (Eds.), Immigration en Belgique francophone, l'état des savoirs. Brussels: Academia-Bruylant.

Jacobs, D., \& Rea, A. (2005). Construction et importation des classements ethniques. Allochtones et immigrés aux Pays-Bas et en Belgique. Revue Européenne des Migrations Internationales, 21(2), 35-59.

Perrin, N. (2008). Migrations et populations issues de l'immigration en Belgique. Rapport statistique et démographique 2007, Brussels, Centre pour l'Egalité des Chances et la Lutte contre le Racisme.

Perrin, N., \& Poulain, M. (2006). Country report: Belgium. In M. Poulain, N. Perrin, \& A. Singleton (Eds.), Towards harmonised European statistics on international migration. Louvain-laNeuve: Presses universitaires de Louvain. pp. 143-173.

Poulain, M., \& Perrin, N. (2002). The demographic characteristics of immigrant populations in Belgium. In W. Haug, Y. Courbage, \& P. Compton (Eds.), The demographic characteristics of immigrant populations (Population studies no 38). Strasbourg: Council of Europe Publishing.

Poulain, M., \& Perrin, N. (2008). Measuring international migration: A challenge for demographers. In J. Surkyn, P. Deboosere, \& J. Van Bavel (Eds.), Liber Amicorum Ron Lestaeghe: Demographic challenges for the 21st century: A state of the art in demography. Brussels: VUBPRESS Brussels University Press.

Van der Haegen, H. (1990). 'L'influence d'une loi récente sur le profil démographique des étrangers en Belgique. Espace, Populations, Sociétés, 2, 310-315.

Vanderkam, M. (2006). October 2005 consultation on the establishment of origin-based data. In Actes du Colloque Statistiques 'ethniques'. Paris: Maison de la Chimie.

Vertommen, S., Martens, A., \& Ouali, N. (2006). Ethnical topography of the Belgian labour market. Employment, gender, age and ethnicity, Final report, TEF-ULB, CSO-KUL, King Baudouin Foundation. 